\title{
On strongly convex functions
}

\section{JUDIT MAKÓ and ATTILA HÁZY}

\section{ABSTRACT.}

The main results of this paper give a connection between strong Jensen convexity and strong convexity type inequalities. We are also looking for the optimal Takagi type function of strong convexity. Finally a connection will be proved between the Jensen error term and an useful error function.

Acknowledgements. The first named author research was supported by the European Union and the State of Hungary, co-financed by the European Social Fund in the framework of TÁMOP 4.2.4. A/2-11-1-2012-0001 'National Excellence Program'. The second named author research has been supported by the János Bolyai research scholarship of the Hungarian Academy of Sciences.

\section{REFERENCES}

[1] Azócar, A., Giménez, J., Nikodem, K. and Sánchez, J. L., On strongly midconvex functions, Opuscula Math., 31 (2011), No. 1, 15-26

[2] Bernstein, F. and Doetsch. G., Zur Theorie der konvexen Funktionen, Math. Ann., 76 (1915), No. 4, 514-526

[3] Boros, Z., An inequality for the Takagi function, Math. Inequal. Appl., 11 (2008), No. 4, 757-765

[4] Conzález, C., Nikodem, K., Páles, Zs., and Roa, G., Bernstein-Doetsch type theorems for set-valued maps of strongly and approximately convex and concave type, Publ. Math. Debrecen, 84 (2014), 229-252

[5] Hadamard, J., Étude sur les propriétés des fonctions entières et en particulier d'une fonction considérée par Riemann, J. Math. Pures Appl., 58 (1893), 171-215

[6] Házy, A. and Páles, Zs., On approximately t-convex functions, Publ. Math. Debrecen, 66 (2005), 489-501

[7] Makó, J. and Nikodem, K. and Páles, Zs., On strong $(\alpha, \mathbb{F})$-convexity, Math. Inequal. Appl., 15 (2012), 289-299

[8] Makó, J. and Páles, Zs., Approximate convexity of Takagi type functions, J. Math. Anal. Appl., 369 (2010), $545-554$

[9] Makó, J. and Páles, Zs., On ب-convexity, Publ. Math. Debrecen, 80 (2012), 107-126

[10] Makó, J. and Páles, Zs., Approximate Hermite-Hadamard type inequalities for approximately convex functions, Math. Inequal. Appl., 16 (2013), 507-526

[11] Makó, J. and Páles, Zs., On approximately convex Takagi type functions, Proc. Amer. Math. Soc., 141 (2013), 2069-2080

[12] Merentes, N. and Nikodem, K., Remarks on strongly convex functions, Aequat. Math., 80 (2010), 193-199

[13] Ng, C. T. and Nikodem, K., On approximately convex functions, Proc. Amer. Math. Soc., 118 (1993), No. 1, 103-108

[14] Nikodem, K. and Páles, Zs., Characterizations of inner product spaces by strongly convex functions, Banach J. Math. Anal., 5 (2011), No. 1, 83-87

[15] Páles, Zs., The Forty-first International Symposium on Functional Equations, June 8-15, 2003, Noszvaj, Hungary, Aequat. Math., 67 (2004), 285-320

[16] Polyak, B. T., Existence theorems and convergence of minimizing sequences in extremum problems with restrictions, Soviet Math. Dokl., 7 (1966), 72-75

[17] Tabor, Ja. and Tabor, Jó., Generalized approximate midconvexity, Control Cybernet., 38 (2009), No. 3, 655-669

Received: 30.05.2014; In revised form: 17.10.2014; Accepted: 24.10.2014

2010 Mathematics Subject Classification. 39B12, 39B22.

Key words and phrases. Strong convexity, Takagi type functions, Hermite-Hadamard type inequalities.

Corresponding author: Judit Makó; matjudit@uni-miskolc.hu 
[18] Tabor, Ja. and Tabor, Jó., Takagi functions and approximate midconvexity, J. Math. Anal. Appl., 356 (2009), No. 2, 729-737

[19] Takagi. T., A simple example of the continuous function without derivative, J. Phys. Math. Soc. Japan, 1 (1903), 176-177

UNIVERSITY OF MISKOLC

INSTITUTE OF MATHEMATICS

H-3515 MisKolc-EgYeTEMVÁROS, HungARY

E-mail address: \{mat judit, matha\} @uni-miskolc.hu 